\title{
Informational role self-efficacy: a validation in interprofessional collaboration contexts involving healthcare service and project teams
}

\author{
François Chiocchio ${ }^{1 *}$, Paule Lebel ${ }^{2}$ and Jean-Nicolas Dubé ${ }^{3}$
}

\begin{abstract}
Background: Healthcare professionals perform knowledge-intensive work in very specialized disciplines. Across the professional divide, collaboration becomes increasingly difficult. For effective teamwork and collaboration to occur, it is considered necessary for individuals to believe in their ability to draw on their expertise and provide what others need to perform their job well. To date, however, no instruments exist to measure such a construct.

Methods: A two-study design is used to test the psychometric properties, factor structure and incremental validity of a five-item questionnaire measuring informational role self-efficacy.

Results: Based on parallel analysis and exploratory factor analysis, Study 1 shows a robust and reliable onedimensional construct. Study 2 cross-validates this factor structure using confirmatory factor analysis. Study 2 also shows that informational role self-efficacy predicts proactive teamwork behaviors over and above goal similarity, interdependence, coordination and intra-team trust.

Conclusions: The instrument can be used in research to assess an individual's capability beliefs in communicating his/her informational characteristics that are pertinent to the task performance of others. The construct is also shown to have value in team-building exercises.
\end{abstract}

Keywords: Self-efficacy, Expertise, Interprofessional collaboration, Healthcare, Team

\section{Background}

\section{Complexity and informational silos in healthcare}

The expanding rate of new knowledge in technical fields fosters the need for greater specialization and the development of subfields [1]. This phenomenon is echoed in healthcare [2] where healthcare professionals perform complex knowledge-intensive tasks [3]. The more healthcare professionals must train to integrate knowledge vertically and grasp the complexity of their specific profession, discipline or field-digging deeper as they specialize-the more challenging it is for them to integrate knowledge horizontally to collaborate interprofessionally. Hood [4] describes this problem in terms of

\footnotetext{
* Correspondence: francois.chiocchio@telfer.uottawa.ca

${ }^{1}$ Telfer School of Management, Institut de recherche de l'Hôpital Montfort, University of Ottawa, 55 Laurier Avenue East, Ottawa, ON K1N 6N5, Canada Full list of author information is available at the end of the article
}

a "double reflexivity"; a "double hermeneutic". Unfortunately, in healthcare "members of each profession know very little of the practices, expertise, responsibilities, skills, values and theoretical perspectives of professionals in other disciplines" [5] in spite of the fact that communicating about expertise fosters trust [6]. Information about one's training background, expertise and knowledge is in itself a type of knowledge referred to as informational characteristics: the "underlying attributes of individuals (e.g., work experience and education) which, although not immediately detectable, are important in the completion of the task" [7].

One key in helping healthcare professionals to better share informational characteristics and work collaboratively is to examine the core beliefs anchoring their actions. Many studies have shown that if a person believes he/she can perform a specific task well, he/she usually does [8] because 
the belief is accompanied by additional efforts and persistence when facing difficulties [9]. Such beliefs are called selfefficacy. Self-efficacy is an individual-level construct defined as beliefs in one's capabilities to succeed at something specific $[9,10]$. Meta-analyses on the topic show moderate to high corrected correlations in various work settings [11-13]. A specific example in healthcare shows a positive relationship between increases in social service workers' creative self-efficacy and increases in creative problem-solving and innovation [14].

Despite the central role of knowledge integration in interprofessional collaboration there are-to our knowledge-no instruments that measure the underlying beliefs of individuals in sharing their expertise. Achieving this through the development of a robust, specific, short, and one-dimensional measure is therefore the goal of the present study.

\section{Incremental validity over teamwork "building blocks"}

When a new measure is introduced, a stringent verification of its utility is to test for incremental validity; that is, to ask whether the measure adds to the prediction of a criterion above what can be predicted by existing phenomena and measures [15]. Four such criteria are crucial in predicting individual behaviors of teamwork and collaboration: goal similarity, interdependence, coordination, and trust.

A team is a collection of individuals united by a common goal and task interdependence [16, 17]. "Shared goals are what make collaboration 'collaborative.' Without at least one shared goal or endpoint, there would be no reason for two or more entities to work together at all" [18]. Team effectiveness hinges on dynamic and adaptive management of interdependencies [19]. Clarifying interdependences between team mates with different roles, and explicitly ironing out work processes through task-oriented coordination lead to team effectiveness [20]. Trust is another construct a new measure should add value to. Trust is crucial in high autonomy teams engaged in ambiguous, unstructured and novel situations [21]. An emergent state resulting from social interactions over time [22], trust derives from behaviour reliability (i.e., calculus-based trust) or from shared values and ideas (i.e., identification-based trust) [23]. Crucially, trust is also about people understanding each other-understanding without which individuals "will have trouble benefiting from the expertise of others" [24]. Attributions of trustworthiness (or lack thereof) can be based on a mix of previously held beliefs about another group (e.g., a professional group) and further thought processes prompted by new information about that group [25]. In healthcare settings particularly, trust is based on individuals manifesting competence including how competence is communicated [26]. Consequently, we posit that:
Informational role self-efficacy will demonstrate incremental validity over perceptions of goal similarity, interdependence, coordination, and intra-team trust, in predicting proactive team behaviors.

Two studies are needed to test this hypothesis, the first to develop the instrument and provide solid psychometric properties, and the second to cross-validate the instrument's properties with a new sample and test for incremental validity.

\section{Method \\ Study 1 \\ Construct definition and instrument development}

Based on Jehn, Bezrukova, and Thatcher's definition of informational characteristics (e.g., work experience and education) [7], on Murphy and Jackson's definition of a work role as "the total set of performance responsibilities associated with one's employment" [27], on Conway's definition of task performance as "job-specific behaviors including core job responsibilities, for which the primary antecedents are likely to be ability and experience" [28], and on self-efficacy's focus on specific beliefs in one's capabilities to produce given attainments [9], we define informational role self-efficacy as an individual's capability beliefs in communicating his/her informational characteristics that are pertinent to the task performance of others.

In developing a preliminary version of the scale, we were led by three guiding principles relevant to scale construction in general and self-efficacy scale development in particular. These three guiding principles are practicality, conceptual footing, and technical quality.

In terms of practicality, scales need to be developed with a specific intent which then becomes the backdrop against which its validation is conducted and assessed [29]. As such, assessing behaviors provide concrete anchors useful for self-regulation and feedback. Low scores point to the need to build capability for specific behaviors. The first two authors conducted discussions with healthcare professionals and academics to bring forward examples of behavioral manifestations indicative of an individual's contribution to taskwork and teamwork in terms of informational characteristics, with an emphasis on manifestations that are perceptible across professional and disciplinary boundaries.

The second guiding principle refers to the conceptual footing on which the scale is erected. In parallel to the inductive approach just described, and because development of the instrument must consider content validity [30], we adopted a deductive framework based on two sets of concepts. The first concept is that items should address the efficacy domain very specifically and reflect behaviors or actions that are under one's control, following Bandura [31]. The second concept is teamwork and 
collaboration which represents the target context in which individuals are expected to function. Accordingly, the first two authors scanned the literature for relevant behavioral indicators and discussed corresponding examples.

The third and final guiding principle pertains to technical quality. Capability statements must be unambiguous (e.g., the survey must avoid double-barrel questions), have fewer than 15 words, contain only one verb and employ the active voice [30,32]. The response scale must be positive only, allow for sufficient variability, and ask people to self-assess on what they can or cannot do [31].

With these inductive, deductive, and technical constraints in mind, the first two authors developed a response scale and wrote 11 capability statements.

\section{Participants and procedures}

Study 1 adhered to the Helsinki Declaration and was granted ethics approval CHUM-09.287 by the Centre hospitalier de l'Université de Montréal. Three hundred and eleven (311) critical care professionals from four intensive care units at the hospital signed a consent form and agreed to complete a paper-and-pencil questionnaire. In addition to basic demographic questions (i.e., age, sex), they answered the 11 professional role self-efficacy items.

We examined responses for missing values, univariate, and multivariate normality [33]. Among 3,421 answers collected (i.e., 311 participants X 11 items), 22 (0.64 \%) were incomplete and were replaced by the mean. Inspection of each item's distribution revealed normal skewness and kurtosis for five items. The other six items were removed from further analysis. Multivariate normality tests using Mahalanobis distance revealed 21 participants who exceeded the cut-off value of 20.515 for 5 item questionnaires; data from these participants was deleted.

The final sample consisted of 290 participants: 69 men (23.8\%) and 221 women (76.2\%) working together in three categories: physicians $(N=44,15.2 \%)$, nurses $(N=175$, $60.3 \%)$, and other critical care professionals $(N=71$, $24.5 \%)$. The proportion of men and women differs as a function of profession $\left(\chi_{(2)}^{2}=35.8 ; p<0.005\right)$, with more women working as nurses and other professionals (e.g., pharmacists, respiratory therapists) than physicians (i.e., intensivists, fellows, residents). Overall, participants had a mean age of $36.5(S D=9.9)$.

\section{Study 2}

\section{Participants and procedures}

Study 2 adhered to the Helsinki Declaration and was granted ethics approval CERFAS-2009-10-050-A by the Faculté des Arts et des Sciences de l'Université de Montréal. Data was collected as part of a larger research project which examined the efficiency and efficacy of interprofessional healthcare teams involved in a project [34]. The researchers contacted the human resource departments of several healthcare establishments in a large North-American city to identify teams comprised of at least five members representing at least three healthcare professions or disciplines. In order to participate, the teams could not be related to Study 1 and they had to be involved in a project. Participants working on 14 projects in nine establishments agreed to take part in the study. An example of a project was to implement fluid interprofessional evaluative processes for adult psychiatric patients requiring specialized care for cardio-metabolic pathologies. Each participant signed a consent form. In order to avoid common method variance issues [35] informational role self-efficacy was assessed before or in the early stage of the project and teams' existence. All other variables were measured, on average, 18.4 weeks later $(S D=8.2)$.

Because we used electronic questionnaires, there were no missing data within each measurement time. All variables showed normal univariate distributions. Multivariate normality tests using Mahalanobis distance did not reveal multivariate outliers [33]. In spite of the fact that 109 persons participated at Time 1, 77 persons responded at the two measurement times: 22 men $(28.6 \%)$ and 55 women $(71.4 \%)$ working as physicians $(N=14,18.2 \%)$, nurses $(N=17,22.1 \%)$, other professionals $(N=42,54.5 \%)$, and support personnel $(N=4$, $5.2 \%)$. The proportion of men and women differed as a function of profession $\left(\chi_{(3)}^{2}=18.3 ; p<0.005\right)$ with more men in the physician category. Other descriptive statistics and reliabilities are shown in Table 1.

\section{Measures}

In addition to the five informational role self-efficacy items shown in the Additional file 1, study participants answered to additional scales. We measured task interdependence with Campion, Medsker, and Higgs's [36] 3-question scale (e.g., Within my project team, jobs performed by members are related to one another). We measured goal similarity using Jehn's [37] 3-item measure of this construct (e.g., In my project team, we have similar goals). Intra-team trust was measured using Simons and Peterson's [38] 5-item measure (e.g., We are all certain that we can fully trust each other). These three instruments used a 5-point response format (i.e., $1=$ strongly disagree; $5=$ strongly agree). Coordination was measured with an instrument validated in ongoing service delivery and project contexts [39] (e.g., In my team we discuss information on 'who does what') using a frequency response format (i.e., $1=$ never or almost never; $2=$ occasionally. $3=$ relatively often; $4=$ often; $5=$ very often). Individual-level performance behaviors relevant to teamwork are taken from Griffin et al. [40]. We used their 3-item proactivity scale (e.g., I suggested ways to make 
Table 1 Descriptive statistics and correlations among Study 2 variables $(N=77)$

\begin{tabular}{|c|c|c|c|c|c|c|c|c|c|c|}
\hline & $M(S D)$ & 1 & 2 & 3 & 4 & 5 & 6 & 7 & 8 & 9 \\
\hline 1. Age & $42.33(10.5)$ & - & & & & & & & & \\
\hline 2. Sex & - & .068 & - & & & & & & & \\
\hline 3. Profession & - & $-.226^{*}$ & -.146 & - & & & & & & \\
\hline 4. Informational role self-efficacy & $79.4(13.3)$ & .174 & -.152 & .142 & .924 & & & & & \\
\hline 5. Inter-dependence & $3.72(0.69)$ & .183 & -.021 & -.043 & $.228^{*}$ & .689 & & & & \\
\hline 6. Goal similarity & $3.90(0.54)$ & .222 & $-.229 *$ & -.071 & .198 & $.440^{* *}$ & .785 & & & \\
\hline 7. Explicit coordiation & $3.26(0.98)$ & .136 & -.189 & .084 & .004 & $.261^{*}$ & $.458^{* *}$ & .914 & & \\
\hline 8. Intra-team trust & $4.11(0.62)$ & .076 & -.158 & -.003 & $.320^{* *}$ & .079 & $.336^{* *}$ & $.243^{*}$ & .890 & \\
\hline 9. Proactive team performance. & $3.27(1.07)$ & $.314^{*}$ & .051 & -.009 & $.388^{* *}$ & $.236^{*}$ & $.402^{* *}$ & $.418^{* *}$ & $.406^{* *}$ & .928 \\
\hline
\end{tabular}

Note

Sex: 1 = Women, 2 = Men; Profession 1 = Physicians, 2 = Nurses, $2=$ Professionals, $4=$ Support

Diagonal shows Cronbach's alphas

${ }^{*} p<0.05$; ${ }^{* *} p<0.01$

our team more effective) with the same frequency answer format as for coordination.

\section{Results}

\section{Study 1}

To assess the stability of the scale across gender and profession, we conducted six principal component and factor analyses: one with the total sample and five with subsamples of nurses, physicians, professionals, men, and women only. Because of the inappropriateness of using the "eigenvalue $>1$ rule" to determine the number of factors present [41], we performed parallel analysis for all six principal component analyses using Hayton, Allen, and Scarpello's [42] statistical routines. These analyses showed that only one factor is present overall and within each five sub-samples. We then proceed with principal axis factor analyses specifying a single factor. Results appear in Table 2. Together, these results show very strong support for a short single-factor construct measured reliably across profession and gender.

\section{Study 2}

Given the single-factor structures seen across subsamples in Study 1, a strong test of the measurement model and single-factor theoretical structure involves using confirmatory factor analysis to cross-validate Study 1's results onto Study 2's sample. Confirmatory factor analysis shows the single-factor structure adjusts well to the data given the relatively small sample size (i.e., $\chi^{2}(5)=$ $6.23 ; p=0.28 ; \mathrm{CFI}=0.983 ; \mathrm{NNF}=0.993 ; \mathrm{NNFI}=0.993$; IFI $=0.996$; SRMR $=0.02$, and RMSEA $=0.05$ with $90 \%$ $\mathrm{CI}$ between 0.00 and 0.155 ). Table 3 shows incremental validity evidence; that is the extent to which informational role self-efficacy contributes to the prediction of dependent variables over control variables and teamwork "building blocks". We can see that informational role selfefficacy is a positive predictor of intra-team trust (Beta = $0.308, p<0.01)$ adding $7.3 \%(p<0.05)$ variance over and above what age, sex, profession, goal similarity, interdependence, coordination, and intra-team trust already contribute to the prediction of proactive performance. Our hypothesis is supported by the results.

\section{Discussion}

\section{Implications for research}

We see at least two streams for future direction in research: team type and power heterarchy. First, because ongoing service delivery and project work are different forms of work [43] healthcare professionals involved in one may not play the same roles when involved in the other

Table 2 Summary of Study 2's principal axis factor analyses

\begin{tabular}{|c|c|c|c|c|c|c|}
\hline & $\begin{array}{l}\text { Complete sample } \\
(N=290)\end{array}$ & $\begin{array}{l}\text { Nurses } \\
(N=175)\end{array}$ & $\begin{array}{l}\text { Physicians } \\
(N=44)\end{array}$ & $\begin{array}{l}\text { Profes. } \\
(N=71)\end{array}$ & $\begin{array}{l}\text { Men } \\
(N=69)\end{array}$ & $\begin{array}{l}\text { Women } \\
(N=221)\end{array}$ \\
\hline Kaiser-Meyer-Olkin index & 0.893 & 0.894 & 0.819 & 0.844 & 0.883 & 0.887 \\
\hline Barlett's test of sphericity & $1211.4^{*}$ & $705.7^{*}$ & $190.9^{*}$ & $273.6^{*}$ & $268.5^{*}$ & $884.7^{*}$ \\
\hline$\%$ of total variance explained & 74.6 & 73.7 & 75.1 & 71.2 & 73.8 & 73.3 \\
\hline Cronbach's alpha & 0.936 & 0.933 & 0.934 & 0.924 & 0.933 & 0.932 \\
\hline$M$ & 76.84 & 73.66 & 83.25 & 80.70 & 83.15 & 74.87 \\
\hline SD & 14.51 & 15.04 & 12.71 & 11.90 & 12.15 & 14.65 \\
\hline
\end{tabular}


Table 3 Hierarchical multiple regression predicting proactive team performance in Study $2(N=77)$

\begin{tabular}{llll}
\hline & \multicolumn{3}{l}{ Standardized Beta } \\
\cline { 2 - 4 } & Model 1 & Model 2 & Model 3 \\
\hline Control variables & & & \\
Age & $0.327^{* *}$ & $0.209^{*}$ & 0.151 \\
Sex & 0.039 & 0.175 & $0.212^{*}$ \\
Profession & 0.070 & 0.033 & -0.027 \\
Teamwork building blocks & & & \\
Goal similarity & & 0.043 & -0.027 \\
Interdependence & & 0.152 & 0.152 \\
Coordination & & $0.267^{*}$ & $0.327^{* *}$ \\
Intra-team trust & & $0.299^{* *}$ & $0.201 \neq$ \\
Informational role self-efficacy & & & $0.308^{* *}$ \\
$R^{2}$ & $0.104^{*}$ & $0.378^{* *}$ & $0.451^{* *}$ \\
$\triangle R^{2}$ & & $0.274^{* *}$ & $0.073^{*}$ \\
\hline
\end{tabular}

Note

Sex: $1=$ Women, $2=$ Men; Profession $1=$ Physicians, $2=$ Nurses,

$2=$ Professionals, $4=$ Support

$\neq p=0.053 ;{ }^{*} p<0.05 ;{ }^{* *} p<0.01$

[44]. In healthcare service work, individuals acquire professional expertise early on in their training and this is an important factor in the formation of professional boundaries. Because interprofessional collaboration is seen as a determinant of high quality patient care [45], one's ability to share expertise across expertise-based knowledge silos is very important. However, because project work primarily centres on organisational issues (i.e., "fixing" the system) rather than directly focussed on patient care (i.e., "fixing" the patient), healthcare expertise is still necessary when working on a project but less so than when providing healthcare to patients. Accordingly, we expect that the impact of informational role self-efficacy will be stronger in regular ongoing healthcare service work compared to project work.

Second, power heterarchy within teams is "a relational system in which the relative power among team members shifts over time as the resources of specific team members become more relevant (and the resources of other members become less relevant) because of changes in the situation or task" [46]. Power dynamics among physicians and nurses is a well-documented inhibitor of interprofessional collaboration in ongoing healthcare service work [5]. Since information is a resource and a form of power [47], we suggest future studies should test whether minimal interprofessional collaboration occurs because of nurses' thwarted informational role selfefficacy. If so, building capacity beliefs in nurses should improve their collaborative behaviors.

\section{Implications for practice}

Organizations can shape employees' sense of efficacy towards desired performance outcomes [14]. Organizations can also engage in team-level activities. Discussing the five behaviors of our scale in a team-building exercise is pertinent for two reasons. First, the five behaviors relate to roles and communication, which is significant in light of a recent meta-analysis showing that team-building has an important effect on individuals' role clarification and communication [48]. Second, team members tend not to share what is unique to each other and prefer discussing what is common to the team [49]. Consequently, it is important to make a conscious effort to stimulate team discussions on the informational roles of individual team members because, by definition, these roles will vary according to differences in individual expertise. These two reasons concur to suggest that a group discussion followed by an action plan aiming at increasing the quantity and quality of the five behaviors of our scale are likely to have a positive impact on how individuals collaborate.

\section{Limitations and future research directions}

This study has three limitations, each with implications for future research. First, the validity evidence is limited to a single method. Although measures are separated in time by 18 weeks on average, there is nevertheless a possible method effect [35]. Future studies should measure dependent variables with a variety of methods (e.g., questionnaires, observations, interviews). Second, our sample size for Study 2 is small which hinders generalizability. Third, informational role self-efficacy is an individual-level construct and our studies were not designed to draw conclusions at the team level. While we were careful to interpret results in terms of individual perceptions of team phenomena [50] and used instruments designed to assess individual behavior manifestation and/or perceptions pertinent to the team context [40], a worthy area of future research would be to integrate our measure in multi-level designs [51]. One such study could measure the relationship between (individual-level) informational role selfefficacy and task performance as a function of collective efficacy (group level). Collective efficacy is a shared belief that the team is able to perform effectively [52-54]. It is logical to hypothesize that the relationship between informational role self-efficacy and task performance will be stronger in teams that rate high in collective efficacy compared to teams with low collective efficacy. Despite these limitations, we demonstrated that informational role selfefficacy is a measurable single-factor individual-level construct and is a correlate and predictor of important phenomena necessary in today and tomorrow's diversified and dynamic work environment.

\section{Conclusion}

These studies are the first to address one's predisposition and capability beliefs regarding communicating the expertise that others need to perform their job well with 
the introduction of an instrument that measures informational role self-efficacy. Cross-validation evidence using exploratory and confirmatory factor analyses supports a robust one-dimensional construct measured with a short 5item behavioral self-assessment. Over an 18-week period, informational role self-efficacy adds variance to the prediction of perceptions proactivity behaviors over and above perceptions of shared goals, interdependence, coordination, and intra-team trust. These results suggest the instrument will have value in future theoretical and conceptual work as well as in practical contexts focusing on interprofessional collaboration.

\section{Availability of data and materials}

Data is not available publicly because informed consent did not include publication of raw data.

\section{Additional file}

Additional file 1: Informational role self-efficacy scale. (DOC 33 kb)

\section{Competing interests}

The authors declare that they have no competing interests.

\section{Author's contributions}

FC conducted the analyses and wrote the paper. FC and PL collaborated to collect Study 2's data. PL and JND collaborated to collect Study 1's data. All contributed to the design of the studies and all offered critical appraisals of the manuscript. All authors read and approved the final manuscript.

\section{Acknowledgements}

This paper was funded by a research grant from the Project Management Institute and by the Centre de pédagogie appliquée aux sciences de la santé de l'Université de Montréal.

\section{Author details}

${ }^{1}$ Telfer School of Management, Institut de recherche de I'Hôpital Montfort, University of Ottawa, 55 Laurier Avenue East, Ottawa, ON K1N 6N5, Canada. ${ }^{2}$ Department of Family Medicine and Emergency Medicine, Université de Montréal, Montréal, Canada. ${ }^{3}$ Internal Medicine Division and Critical Care Division Centre intégré universitaire de santé et de services sociaux de la Mauricie-et-du-Centre-du-Québec, Trois-Rivières, Canada.

Received: 29 January 2016 Accepted: 14 April 2016

Published online: 27 April 2016

\section{References}

1. Edmondson AC, Nembhard IM. Product Development and Learning in Project Teams: The Challenges Are the Benefits*. J Prod Innov Manag. 2009; 26(2):123-38.

2. Stitzenberg KB, Sheldon GF. Progressive Specialization Within General Surgery: Adding to the Complexity of Workforce Planning. J Am Coll Surg. 2005;201(6):925-32.

3. Fay D, Borrill C, Amir Z, Haward R, West MA. Getting the most out of multidisciplinary teams: A multi-sample study of team innovation in health care. J Occup Organ Psychol. 2006;79(4):553-67.

4. Hood R. A critical realist model of complexity for interprofessional working. J Interprof Care. 2012;26(1):6-12.

5. San Martin Rodriguez L, Beaulieu M-D, D'Amour D, Ferrada-Videla M. The determinants of successful collaboration: A review of theoretical and empirical studies. J Interprof Care. 2005;19(2):132-47.

6. MacNaughton K, Chreim S, Bourgeault IL. Role construction and boundaries in interprofessional primary health care teams: a qualitative study. BMC Health Serv Res. 2013;13(1):486.
7. Jehn KA, Bezrukova K, Thatcher S. Conflict, diversity, and faultlines in workgroups. In: De Dreu CKW, Gelfand MJ, editors. The Psychology of Conflict Management in Organizations. edn. New York: Laurence Erlbaum; 2008. p. 179-210.

8. Tims M, Bakker AB, Derks D. Daily job crafting and the self-efficacy performance relationship. J Manag Psychol. 2014;29(5):490-507.

9. Bandura A. Self-efficacy - The exercise of control. New York: W.H. Freeman and Company; 1997.

10. Bandura A. Social foundation of thought and action: A social cognitive theory. Englewood Cliffs, NJ: Prentice-Hall; 1986.

11. Bandura A, Locke EA. Negative self-efficacy and goal effects revisited. J Appl Psychol. 2003;88(1):87

12. Stajkovic AD, Luthans F. Self-efficacy and work-related performance: A metaanalysis. Psychol Bull. 1998;124(2):240.

13. Judge TA, Bono JE. Relationship of core self-evaluations traits-self-esteem, generalized self-efficacy, locus of control, and emotional stability — with job satisfaction and job performance: A meta-analysis. J Appl Psychol. 2001;86(1):80.

14. Tierney P, Farmer SM. Creative self-efficacy development and creative performance over time. J Appl Psychol. 2011;96(2):277-93.

15. Hunsley J, Meyer GJ. The Incremental Validity of Psychological Testing and Assessment: Conceptual, Methodological, and Statistical Issues. Psychol Assess. 2003;15(4):446-55.

16. Cohen SG, Bailey DE. What makes teams work: Group effectiveness research from the shop floor to the executive suite. J Manage. 1997:23(3):239-90.

17. Hackman RJ, editor. Groups That Work (And Those That Don't): Creating Conditions For Effective Teamwork. San Francisco, CA: Jossey-Bass; 1990.

18. Bedwell WL, Wildman JL, DiazGranados D, Salazar M, Kramer WS, Salas E. Collaboration at work: An integrative multilevel conceptualization. Hum Resour Manag Rev. 2012;22(2):128-45.

19. Kozlowski SWJ, Gully SM, Nason ER, Smith EM. Developing adaptive teams: A Theory of compilation and performance across levels and time. In: Pulakos ED, Ilgen DR, editors. The Changing Nature of Performance. edn. San Francisco: Jossey-Bass; 1999. p. 240-92.

20. Deneckere S, Euwema M, Lodewijckx C, Panella M, Mutsvari T, Sermeus W, Vanhaecht K. Better interprofessional teamwork, higher level of organized care, and lower risk of burnout in acute health care teams using care pathways: a cluster randomized controlled trial. Med Care. 2013;51(1):99-107.

21. Kiffin-Petersen SA, Cordery JL. Trust, individualism and job characteristics as predictors of employee preference for teamwork. Int J Hum Resour Manag. 2003;14(1):93-116.

22. Kozlowski SWJ, Bell BS. Work groups and teams in organizations. In: Borman WC, Ilgen DR, Klimoski RJ, Weiner IB, editors. Handbook of Psychology : Industrial and Organizational Psychology. Volume 12, edn. London: Wiley; 2003. p. 333-75.

23. Pullon S. Competence, respect and trust: Key features of successful interprofessional nurse-doctor relationships. J Interprof Care. 2008;22(2):133-47.

24. Tyler TR. Trust within organisations. Pers Rev. 2003:32:556-68.

25. Williams M. In whom we trust: Group membership as an affective context for trust development. Acad Manag Rev. 2001;26(3):377-96.

26. McDonald J, Jayasuriya R, Harris MF. The influence of power dynamics and trust on multidisciplinary collaboration: a qualitative case study of type 2 diabetes mellitus. BMC Health Serv Res. 2012;12(1):63.

27. Murphy PR, Jackson SE. Managing role performance: Challenges for twentyfirst-century organizations and their employees. In: Pulakos ED, Ilgen DR, editors. The Changing Nature of Performance. edn. San Francisco: JosseyBass; 1999. p. 325-65.

28. Conway JM. Distinguishing contextual performance from task performance for managerial jobs. J Appl Psychol. 1999;84(1):3-13.

29. Chiocchio F. A model for integrating theory and practice of psychometry. Int J Psychol. 1996;31(3-4):483.

30. Hinkin TR. A review of scale development practices in the study of organizations. J Air Waste Manage Assoc. 1995;21(5):967-88.

31. Bandura A. Guide for construction self-efficacy scales. In: Urdan T, Pajares F, editors. Self-Efficacy Beliefs of Adolescents. edn. Charlotte, NC: Information Age Publishing; 2006. p. 307-37.

32. Behling O, Law KS. Translating Questionnaires and Other Research Instruments. Thousand Oaks, CA: Sage; 2000

33. Tabachnick BG, Fidell LS. Using multivariate statistics. 6th ed. Boston: Pearson; 2013

34. Chiocchio F, Rabbat F-X, Lebel P. Multi-level efficacy evidence of a combined interprofessional collaboration and project management training program for healthcare project teams. Proj Manag J. 2015;46(4):20-34. 
35. Podsakoff PM, Mackenzie SB, Lee JY, Podsakoff NP. Common method biases in behavioral research: A critical review of the literature and recommended remedies. J Appl Psychol. 2003;88(5):879-903.

36. Campion AC, Medsker GJ, Higgs AC. Relations between work group characteristics and effectiveness: Implications for designing effective work groups. Pers Psychol. 1993;46:823-50.

37. Jehn KA. A multimethod examination of the benefits and detriments of intragroup conflict. Adm Sci Q. 1995;40(2):256-82.

38. Simons TL, Peterson RS. Task conflict and relationship conflict in top management teams: The pivotal role of intragroup trust. J Appl Psychol. 2000;85(1):102-11.

39. Chiocchio F, Grenier S, O'Neill TA, Savaria K, Willms DJ. The effects of collaboration on performance: A multilevel validation in project teams. IJPOM. 2012;4(1):1-37.

40. Griffin MA, Neal A, Parker SK. A new model of work role performance: Positive behavior in uncertain and interdependent contexts. Acad Manag J. 2007:50(2):327-47.

41. Lance CE, Butts MM, Michels LC. The Sources of Four Commonly Reported Cutoff Criteria: What Did They Really Say? Organ Res Methods. 2006;9(2):202-20

42. Hayton JC, Allen G, Scarpello V. Factor Retention Decisions in Exploratory Factor Analysis: a Tutorial on Parallel Analysis. Organ Res Methods. 2004;7(2):191-205.

43. Hobbs B. The specifics of project contexts. In: Chiocchio F, Kelloway EK, Hobbs B, editors. The Psychology and Management of Project Teams. edn. New York: Oxford University Press; 2015.

44. Chiocchio F, Richer M-C. From multi-professional to trans-professional healthcare teams: The critical role of innovation projects. In: Gurtner S, Soyez K, editors. Challenges and Opportunities in Health Care Management. edn. Cham, Switzerland: Springer; 2015. p. 161-9.

45. D'Amour D, Ferrada-Videla M, San Martin Rodriguez L, Beaulieu M-D. The conceptual basis for interprofessional collaboration: Core concepts and theoretical frameworks. J Interprof Care. 2005;19(2):116-31.

46. Aime F, Humphrey S, DeRue DS, Paul JB. The Riddle of Heterarchy: Power Transitions in Cross-Functional Teams. Acad Manag J. 2014:57(2):327-52.

47. Galbraith JR. Organization Design: An Information Processing View. The Army Organizational Effectiveness Journal. 1984:8(1):21-6.

48. Klein C, DiazGranados D, Salas E, Le H, Burke CS, Lyons R, Goodwin GF. Does Team Building Work? Small Group Res. 2009:40:181-222.

49. Stasser G, Vaughan SI, Stewart DD. Pooling Unshared Information: The Benefits of Knowing How Access to Information Is Distributed among Group Members. Organ Behav Hum Decis Process. 2000;82(1):102-16.

50. Chan D. Functional relations among constructs in the same content domain at different levels of analysis: A typology of composition models. J Appl Psychol. 1998;83(2):234-46.

51. Kozlowski SWJ, Klein KJ. A multilevel approach to theory and research in organizations: Contextual, temporal, and emergent processes. In: Klein KK, Kozlowski SWJ, editors. Multilevel theory, research, and methods in organizations. edn. San Francisco: Jossey-Bass; 2000. p. 3-90.

52. Gibson CB. Do They Do What They Believe They Can? Group Efficacy and Group Effectiveness across Tasks and Cultures. Acad Manag J. 1999;42(2):138-52.

53. Lin C-P, Baruch Y, Shih W-C. Corporate social responsibility and team performance: The mediating role of team efficacy and team self-esteem. J Bus Ethics. 2012;108(2):167-80.

54. Porter CO. Goal orientation: effects on backing up behavior, performance, efficacy, and commitment in teams. J Appl Psychol. 2005;90(4):811.

\section{Submit your next manuscript to BioMed Central and we will help you at every step:}

- We accept pre-submission inquiries

- Our selector tool helps you to find the most relevant journal

- We provide round the clock customer support

- Convenient online submission

- Thorough peer review

- Inclusion in PubMed and all major indexing services

- Maximum visibility for your research

Submit your manuscript at www.biomedcentral.com/submit

) Biomed Central 